\title{
MiR-98 Protects Nucleus Pulposus Cells against Apoptosis by Targeting TRAIL in Cervical Intervertebral Disc Degeneration
}

\author{
Shimin Xu, Yuezhong Li, Junshan Zhang, Zhiwei Li, and Yanping Xing \\ Department of Spine Surgery, Weifang People's Hospital, No. 151, Guangwen Street, Kuiwen District, Weifang City, \\ Shandong 261041, China \\ Correspondence should be addressed to Yanping Xing; xyp831209@163.com
}

Received 13 September 2021; Revised 25 October 2021; Accepted 28 October 2021; Published 25 January 2022

Academic Editor: Kalidoss Rajakani

Copyright (c) 2022 Shimin Xu et al. This is an open access article distributed under the Creative Commons Attribution License, which permits unrestricted use, distribution, and reproduction in any medium, provided the original work is properly cited.

The excessive apoptosis of nucleus pulposus (NP) cells is a major risk factor in the progress of cervical intervertebral disc degeneration (IVDD). In this study, we investigated the impact of miR-98 on apoptosis of NP cells and the potential molecular mechanisms. Lipopolysaccharide (LPS) was used to establish an NP cell IVDD model. The sponging effect of miR-98 on TRAIL $3^{\prime}$ UTR was predicted by ENCORI and assessed by the dual-luciferase reporter gene system. The expression levels of miR-98, TRAIL, and TRAIL pathway-related genes were tested by qRT-PCR, Western blot, and immunofluorescence analysis. Cell apoptosis was analyzed by Hoechst 33258 staining and flow cytometry. Cell viability was analyzed by MTT assay. It was found that the expression level of miR-98 was downregulated, while the level of TRAIL was upregulated in IVDD tissues, and their levels were negatively and positively associated with the clinical MRI grade, respectively. The LPS treatment resulted in a significant decrease of the miR-98 expression level and an increase of the TRAIL expression level in NP cells. miR-98 reduced NP cell apoptosis under LPS treatment in vitro. miR-98 directly targeted TRAIL. Moreover, the mRNA and protein levels of DR5, FADD, cleaved caspase8, cleaved caspase3, and cleaved PARP were downregulated by miR-98 overexpression. Overexpression of TRAIL partially reversed the suppressive roles of miR-98 on cell apoptosis and activation of the TRAIL pathway. We concluded that miR-98 inhibited apoptosis of NP cells by inactivating the TRAIL pathway via targeting TRAIL in IVDD NP cells. These results indicated that miR98 might be a therapeutic target for IVDD.

\section{Introduction}

Cervical intervertebral disc degeneration (IVDD) is a common clinical disease, and it affects more than $62 \%$ of patients whose age was over 40 years, with or without any clinical symptom [1]. IVDD is a causative factor of cervical spondylosis, leading to upper limb numbness, neck or back pain, and dizziness [2]. Many patients with late-stage or severe IVDD will develop cervical spinal stenosis and herniated disc, requiring surgical intervention and causing greater financial burden $[2,3]$. Various risk factors affect IVDD including genetic predisposition, mechanical stress, aging, chemical stimulation, and so on [4]. More and more studies indicated that the excessive apoptosis of nucleus pulposus (NP) cells had a vital influence on the progress of IVDD [5]. Thus, it is an important strategy to block the apoptotic pathway and suppress the apoptosis of NP cells for the prevention and treatment of IVDD.

As the small, single-stranded RNAs, microRNAs (miRNAs) could suppress gene expression at the posttranscriptional regulation process or induce target gene mRNA degradation [6]. miRNAs have a vital regulatory role in differentiation, apoptosis, proliferation, carcinogenesis, and drug resistance $[7,8]$. Remarkably, accumulating evidence indicates that the levels of miRNAs are frequently dysregulated in intervertebral disc degeneration, which can induce NP cell apoptosis and destroy the balance of cellmatrix synthesis and degradation [7-9], for instance, Sun et al. confirmed that miR-181a directly targeted TRAIL and alleviated the disarrangement of intervertebral disc tissue in intervertebral disc degeneration mice [7]; miR-133a was demonstrated to significantly promote type II collagen 
expression by targeting MMP9 in NP cells [8]. It has also been found that the expression of miR-98 was dropped in IVDD tissues [9]. It was also reported that the dysregulated miR-98 could decrease type II collagen level, leading to intervertebral disc degeneration through blocking the IL-6/ STAT3 signaling pathway [9]. It has also been confirmed that miR-98 prevented the unrestricted expansion of diabetogenic cytotoxic T cells by directly targeting TRAIL and Fas and blocking the apoptosis signaling pathways [10]. So, we hypothesized that miR-98 could have some potential protective effects via inhibiting the NP cell apoptosis in IVDD.

As the common apoptosis-inducing factor, TRAIL is expressed in various tissues and organs (including intervertebral disc tissues), and it can induce apoptosis of cells via binding to TRAIL-specific receptors [11]. In humans, TRAIL interacts with DR4 and DR5 to transduce apoptosis signals [12]. Then, adapter molecules such as Fas-associated death domain (FADD) as well as signaling molecules such as caspase 8 were recruited to forming a death-inducing signaling complex (DISC), which is initiated by oligomerization of TRAIL receptors. The DISC induces the proximity and cleavage of caspase $8[13,14]$. Once being activated, the cell death signal is transmitted to downstream events by cleaved caspase 8 . Caspase 3 is one of the substream proteins, which in turn cleaves PARP, thereby culminating in the cell apoptosis [15]. It has been reported that cell apoptosis could be regulated by interfering with the TRAIL-signaling pathway. For example, the overexpression of miR-133a promoted TRAIL resistance by targeting DR5 and blocking the TRAIL-signaling pathway in glioblastoma [16]. Besides, miR-25 targeted DR4 and inhibited TRAIL-induced cholangiocarcinoma apoptosis [12]. The expression levels of TRAIL, DR4, and DR5 are increased in intervertebral disk degeneration cells, which are positively correlated to the degenerative state of the disk [12]. Therefore, it may be a key potential application in the treatment of IVDD by targeting TRAIL and blocking the TRAIL-signaling pathway.

LPS $(>1-300 \mathrm{ng} / \mathrm{mL})$ is one of the major components of the Gram-negative bacterial cell wall and is often used as a strong promoter of inflammation, binds to TLR4, leading to the activation of the toll-like receptor signaling pathway [17], which can promote the production of TRAIL [18]. Thus, we established the IVDD model using NP cells treated with LPS. In the current study, we aimed to explore whether miR-98 could target TRAIL in NP cells and assessed the inhibitory impact of miR-98 on NP cell apoptosis stimulated by LPS.

\section{Materials and Methods}

2.1. Human NP Tissue Samples. The methodology of the study was approved by the Research Ethics Committee of Weifang People's Hospital (Weifang, China). To obtain human NP tissue at surgery, we got the written consent form from all subjects or their relatives. There were 20 IVDD patients (IVDD; average age $45 \pm 1.53$; male $=9$, female $=11$ ) who underwent spinal fusion or disc resection surgery to relieve neck or back pain and 20 non-IVDD patients (normal; average age $29 \pm 2.15$; male $=12$, female $=8$ ) who underwent traumatic cervical spine fracture participated in our study. All the patients underwent routine MRI scans of the cervical spine before the surgery; then, the degree of cervical disc degeneration was assessed by a modified Pfirrmann classification according to the T2-weighted images [19]. Then, all NP tissue samples were regrouped based on the MRI score and stored in liquid nitrogen at $-80^{\circ} \mathrm{C}$.

2.2. Cells and Cell Culture. ScienCell Research Laboratories (USA) provided human NP cells. The cells were maintained in DMEM (Gibco, USA) supplementing with 10\% FBS (Gibco, USA) and 1\% antibiotics. The NP cells were treated with $0.01-10 \mu \mathrm{g} / \mathrm{mL}$ of LPS (Sigma-Aldrich, USA) for $12-48 \mathrm{~h}$ to trigger cell inflammation in vitro.

2.3. Cell Transfection. MiR-98 mimics and its control (mimics-NC) were purchased from Applied Biosystems (USA). TRAIL pcDNA 3.1 (pcDNA-TRAIL) was designed and synthesized by GenePharma (China). Lipofectamine 2000 (Thermo Fisher, USA) was used to transfect the miRNAs and pcDNA-TRAIL into NP cells. After $24 \mathrm{~h}$ of transfection, $1 \mu \mathrm{g} / \mathrm{mL}$ LPS (Sigma-Aldrich, USA) was applied to stimulate the cells in DMEM (Gibco, USA). We collected the cells after $24 \mathrm{~h}$ for subsequent experimentation.

2.4. Real-Time Quantitative PCR. To extract RNA from the samples, TRIzol reagent (Thermo Fisher, USA) was used. For small RNA (smaller than 200 nucleotides in size), the mirVana miRNA isolation kit (Austin, USA) was used to isolate small RNA from total RNA. For mRNA, RNA was reversely transcribed into complementary DNA (cDNA) with a reverse transcription cDNA kit (Thermo Fisher, USA). qRT-PCR was conducted via the SYBR-Green PCR SuperMix-UDG kit (Thermo Fisher, USA) under the Opticon RT-PCR Detection System (ABI 7500; Thermo Fisher, USA). For miRNA, the TaqMan microRNA Reverse Transcription Kit (Thermo Fisher, USA) was selected to perform RT reactions. Subsequently, conventional TaqMan PCR (Thermo Fisher, USA) was used to quantify the RT product. U6 and GAPDH were used for normalization. Table 1 provides all the sequences of primers, which were purchased from GenePharma (China). The $2^{-\Delta \Delta \mathrm{Ct}}$ method was used to calculate the relative expression [20].

2.5. Western Blot. After extracted total protein from NP cells and NP tissues with RIPA buffer (Cell Signaling Technology, USA), the samples were transferred into a polyvinylidene fluoride membrane (PVDF, Millipore), and electrophoresis was conducted to separate the samples with a $10 \%$ SDSPAGE gel (Solarbio, China). The protein concentration was quantified by a BCA assay kit (Sigma-Aldrich; USA). The primary antibodies were TRAIL (Rabbit; 3219; $1: 1000$ ), DR5 (Rabbit; 8074; 1:1000), FADD (Rabbit; 2782; 1:1000), caspase8 (Mouse; 9746; $1: 1000$ ), cleaved caspase8 (Rabbit; 8592; 1:1000), caspase3 (Rabbit; 9662; 1:1000), cleaved caspase3 (Rabbit; 9661; 1:1000), PARP (Rabbit; 9532; 1 : 1000), cleaved PRAP (Rabbit; 5625; $1: 1000$ ), and GAPDH 
TABLE 1: The primer sequences.

\begin{tabular}{|c|c|}
\hline Gene & Primer sequence \\
\hline \multirow{2}{*}{ TRAIL } & Forward 5'-GACCTGCGTGCTGATC-3' \\
\hline & Reverse $5^{\prime}$-TAAAAGAAGATGACAG-3' \\
\hline \multirow{2}{*}{$\operatorname{miR}-98$} & Forward $5^{\prime}$-UGAGGUAGUAAGUUGUAUUGUU-3' \\
\hline & Reverse 5'-AACAAUACAACUUCUACCUCA-3' \\
\hline \multirow{2}{*}{ U6 } & Forward: 5'-CGCTTCGGCAGCACATATAC-3' \\
\hline & Reverse: 5'-AAATATGGAACGCTTCACGA-3' \\
\hline \multirow[t]{2}{*}{ GAPDH } & Forward: $5^{\prime}$-GCACCGTCAAGGCTGAGAAC-3' \\
\hline & Reverse: 5'-TGGTGAAGACGCCAGTGGA-3' \\
\hline
\end{tabular}

(Rabbit; 5174; $1: 1000$ ) specific. All antibodies were bought from Cell Signaling Technology, the USA. Then, we added the secondary antibodies (goat anti-mouse/rabbit IgG; Abcam, UK), which were conjugated with horseradish peroxidase (HRP) (CST, USA). ImageJ software (version 5.0; Bio-Rad, the USA) was applied to analyze and quantify the gray value of the strips. GAPDH was used as a control.

2.6. MTT Assay. The cytotoxic assay was detected using an MTT kit (Solarbio, China). The transfected cells were seeded in a 96-well plate in $200 \mu \mathrm{l}$ medium. At the specified point in time, $100 \mu \mathrm{l}$ culture medium containing $20 \mu \mathrm{l}$ MTT was added into each well, and then, the 96-well plates were placed in the incubator. After $4 \mathrm{~h}, 150 \mathrm{ul} /$ well formazan solution was used to dissolve the blue-purple crystals. The optical density value was read using a microplate reader (Thermo Fisher, USA) at $490 \mathrm{~nm}$.

2.7. Hoechst 33258 Staining. Sterile glass coverslips with $24-$ well plates were used for cell seeding, and every well had $5 \times 10^{4}$ cells. After different treatments, the cells were isolated from the medium, fixed using $4 \%$ paraformaldehyde (Solarbio, China) for $15 \mathrm{~min}$, washed using $0.15 \mathrm{~mol} / \mathrm{L} \mathrm{NaCl}$ for 3 times, and stained using $2 \mu \mathrm{g} / \mathrm{mL}$ Hoechst 33258 (Sigma-Aldrich; USA) in HBSS for 5 min. After washing with $0.15 \mathrm{~mol} / \mathrm{L} \mathrm{NaCl}$ for 2 times, the antifade mounting medium (Beyotime, China) was used to mount the coverslips onto slides. The fluorescence microscope (Olympus IX50, Japan) was used to observe the morphologic changes in apoptotic nuclei.

2.8. Flow Cytometry Analysis. Annexin V-FITC-propidium iodide (PI) apoptosis detection reagent (BD Biosciences, USA) was selected to test cell apoptosis as previously described [21]. Briefly, PBS was used to wash the NP cells 3 times, and the NP cells were digested with trypsin $(1 \mathrm{~mL})$ and resuspended using $1 \mathrm{X}$ Annexin binding buffer at $1 \times 10^{5}$ cells $/ 100 \mu \mathrm{l}$. Then, we gathered and stained the cells with Annexin V-FITC and PI for $15 \mathrm{~min}$. Finally, flow cytometry (version 10.0, FlowJo, FACS Calibur ${ }^{\mathrm{TM}}$, BD Biosciences, USA) was used to count the cells.

2.9. Dual-Luciferase Reporter Assay. The putative binding sites of miR-98 in 3'-UTR of TRAIL was predicted by ENCORI. The pMIR-reporter plasmids (Huayueyang, China) named
TRAIL-WT and TRAIL-MUT with wild-type and mutated $3^{\prime}$ UTR of TRAIL mRNA were constructed. Briefly, the mutation site of the binding region of miR-98 in $3^{\prime}$-UTR TRAIL was designed. The cDNA fragments of TRAIL (3'-UTR) containing the wild-type (WT) or mutant-type (MUT) were amplified. Restriction enzyme sites SpeI and Hind III were used to introduce the cDNA fragments into pMIR-reporter. The sequenced luciferase MUT and WT reporter plasmids were, respectively, cotransfected with miR-98 into NP cells. To determine the luciferase activity, the dual-luciferase reporter assay system (Promega, USA) was applied $30 \mathrm{~h}$ after transfection. Renilla luciferase activity was used to normalize the results.

2.10. Immunofluorescent Assay. The NP cells were first fixed in $4 \%$ paraformaldehyde and incubated overnight in primary rabbit polyclonal anti-TRAIL, polyclonal rabbit antiDR5, or anticleaved caspase8 (CST, the USA) antibodies, respectively. On the next day, the cells were treated with the Alexa Fluor ${ }^{\circledR 594}$ labeled conjugated goat-rabbit IgG, and cell nuclei were counterstained with DAPI (Beyotime, China). The results were observed under an Olympus FluoView 2000 laser scanning confocal microscope (Olympus, Japan).

2.11. Statistical Analysis. Statistical analysis was carried out using Prism 8 (GraphPad Software, the USA). To evaluate statistically significant differences between two groups, oneway ANOVA or Student's $t$-test was performed. The chisquare test was used for the comparative analysis of the discontinuous variables (Table 2). The statistically significant differences were indicated by $P<0.05$.

\section{Results}

3.1. The High Expression of TRAIL and Low Expression of miR98 in IVDD Tissues. The expressions of TRAIL and miR-98 and the clinical characteristics of the patients with IVDD were assessed and are given in Table 2. A high TRAIL expression (higher than mean) was correlated with a high MRI grade, while the correlation between the miR-98 level and MRI grade showed the opposite results. However, the levels of miR-98 and TRAIL were not correlated with age, sex, or body mass index.

The relative expressions of miR-98 and TRAIL were detected by qRT-PCR in NP tissues (normal vs. IVDD, Figures 1(a) and 1(b)). The results showed that the expression of miR-98 was significantly lower in IVDD tissues than in the normal control $(P<0.01)$. In contrast, TRAIL mRNA expression was significantly higher $(P<0.01)$. The representative results of Western blot assay confirmed the results of qRT-PCR (Figure 1(c)). Moreover, it showed a negative correlation between the expression of miR-98 and TRAIL expression $(r=-0.5977, P<0.05)$ (Figure $1(\mathrm{~d})$ ).

3.2. Establishment of the IVDD Cell Model. To find the appropriate concentration and treatment time of LPS, we used different LPS concentrations $(0.01-10 \mu \mathrm{g} / \mathrm{mL})$ and treatment 
TABLE 2: Association between miR-98/TRAIL expression and the clinical characteristics of patients with IVDD.

\begin{tabular}{|c|c|c|c|c|c|c|}
\hline \multirow{2}{*}{ Characteristics } & \multicolumn{2}{|c|}{ miR-98 expression } & \multirow{2}{*}{$P$ value } & \multicolumn{2}{|c|}{ TRAIL expression } & \multirow{2}{*}{$P$ value } \\
\hline & Low (12) & High (8) & & Low (7) & High (13) & \\
\hline Ages & & & 0.489 & & & 0.158 \\
\hline$\leq 45$ & 4 & 5 & & 3 & 6 & \\
\hline$>45$ & 8 & 3 & & 4 & 7 & \\
\hline Gender & & & 0.145 & & & 0.325 \\
\hline Male & 7 & 2 & & 5 & 4 & \\
\hline Female & 5 & 6 & & 2 & 9 & \\
\hline Body mass index & & & 0.216 & & & 0.173 \\
\hline$\leq 24 \mathrm{~kg} / \mathrm{m}^{2}$ & 3 & 5 & & 1 & 7 & \\
\hline$>24 \mathrm{~kg} / \mathrm{m}^{2}$ & 9 & 3 & & 6 & 6 & \\
\hline MRI grade & & & $0.028^{*}$ & & & $0.042^{*}$ \\
\hline G (I/II/III) & 2 & 4 & & 3 & 3 & \\
\hline G $(\mathrm{IV} / \mathrm{V})$ & 10 & 4 & & 4 & 10 & \\
\hline
\end{tabular}

${ }^{*} P<0.05$, statistical significance.

periods $(0,12,24$, and $48 \mathrm{~h})$ to stimulate NP cells and assessed the cytotoxic effect using MTT assay. It was found that the viability of NP cells reduced with the increase of LPS concentration and treatment time duration. As shown in Figure 2(a), the cell viability was significantly decreased with $1 \mu \mathrm{g} / \mathrm{mL}(24 \mathrm{~h}$ and $48 \mathrm{~h}$ ) and $10 \mu \mathrm{g} / \mathrm{mL}(24 \mathrm{~h}$ and $48 \mathrm{~h})$ LPS $(P<0.05)$. However, it dropped below $50 \%$ with $1 \mu \mathrm{g} / \mathrm{mL}$ $(48 \mathrm{~h})$ and $10 \mu \mathrm{g} / \mathrm{mL}(24 \mathrm{~h}$ and $48 \mathrm{~h})$ LPS. Then, the expressions of miR-98 and TRAIL in the IVDD cell model treated with LPS were detected. As predicted, qRT-PCR analysis demonstrated that TRAIL expression was upregulated in NP cells stimulated with the increase of LPS concentrations $(0.01-1 \mu \mathrm{g} / \mathrm{mL} ; 24 \mathrm{~h})$, but it dropped under $10 \mu \mathrm{g} / \mathrm{mL}$ LPS treatment (Figure 2(b)), and the results of Western blot assay were consistent with the results of qRTPCR (Figure 2(c)). The highest level of TRAIL expression was observed under $1 \mu \mathrm{g} / \mathrm{mL}$ LPS ( $P<0.01 \mathrm{vs.} \mathrm{the} \mathrm{blank).} \mathrm{By}$ contrast, the level of miR-98 was downregulated with the increase of LPS concentrations (Figure 2(d)). Taken together, the IVDD cell model was successfully established with $1 \mu \mathrm{g} / \mathrm{mL}$ LPS treated for $24 \mathrm{~h}$, and miR-98 was significantly downregulated $(P<0.01)$ and TRAIL was significantly upregulated $(P<0.01)$ in response to LPS stimulation in the IVDD cell model.

\subsection{Overexpression of miR-98 Inhibited LPS-Induced NP Cell} Apoptosis. To examine the role of miR-98 in the apoptosis of LPS-induced NP cells, the cells transfected with mimics-NC and miR-98 mimics were divided into 4 groups (blank, LPS, LPS + mimics-NC, and LPS + miR-98 mimics), and high transfection efficiency was verified by qRT-PCR (Figure 3(a)). The results of MTT assay suggested that the cell viability was significantly reduced under the stimulation of LPS in comparison to the blank $(P<0.01$, Figure $3(\mathrm{~b}))$, while the transfection of miR-98 mimics could significantly increase the cell viability in comparison with the LPS + mimics-NC group $(P<0.01$, Figure $3(b))$. Both flow cytometric analysis and Hoechst 33258 staining were performed, and the results reported that the LPS treatment could significantly increase NP cell apoptosis in comparison to the blank group $(P<0.01$, Figures $3(\mathrm{c})$ and $3(\mathrm{~d}))$. In contrast, the transfection of miR-98 mimics significantly decreased NP cell apoptosis in comparison with the LPS + mimics-NC group $(P<0.01$, Figures $3(\mathrm{c})$ and $3(\mathrm{~d}))$. These results above revealed that miR-98 could increase cell viability and inhibit apoptosis of LPS-induced NP cells.

3.4. MiR-98 Directly Targeted $3^{\prime}$-UTR of TRAIL. To make a further insight into the suppression role of miR-98 on NP cell apoptosis in IVDD, the relationship between TRAIL and miR-98 was investigated. According to the prediction of ENCORI, miR-98 could specifically bind to the $3^{\prime}$-UTR of TRAIL (Figure 4(a)). As shown in Figure 4(b), these predictions were demonstrated by dual-luciferase gene reporter assay in NP cells. The results suggested that the transfection of miR-98 mimics significantly dropped the luciferase activity of the TRAIL-WT group in comparison to the group transfected with mimics-NC $(P<0.01)$. There was no significant difference found between the luciferase activity of the TRAILMUT group transfected with miR-98 mimics or mimics-NC $(P>0.05)$. To verify this result, we assessed the level of TRAIL in NP cells transfected with miR-98 mimics and mimics-NC. The results of qRT-PCR reported that TRAIL was significantly lower in the LPS + miR-98 mimics group than in the LPS + mimics-NC group $(P<0.01$, Figure $4(\mathrm{c}))$. Western blotting and immunofluorescence assay reported similar outcomes $(P<0.01$, Figures $4(\mathrm{~d})$ and $4(\mathrm{e}))$.

3.5. MiR-98 Decreased the Apoptosis of NP Cells by Targeting TRAIL. As the transfection of miR-98 mimics repressed the TRAIL levels in NP cells and inhibited apoptosis of NP cells, we then determined whether the transfection of pcDNATRAIL could counteract the inhibitory impact of miR-98 on apoptosis of NP cells. The NP cells stimulated with LPS were divided into 5 groups (blank, LPS + pcDNA-NC, LPS + pcDNA-TRAIL, LPS + miR-98 mimics + pcDNA-NC, and LPS + miR-98 mimics + pcDNA-TRAIL). The results of qRT-PCR and Western blot assay showed that pcDNATRAIL has been successfully transfected into the NP cells and effectively expressed (Figures 5(a) and 5(b)). We further detected the viability and apoptosis of LPS-treated NP cells, and the results of MTT assays and flow cytometry revealed 


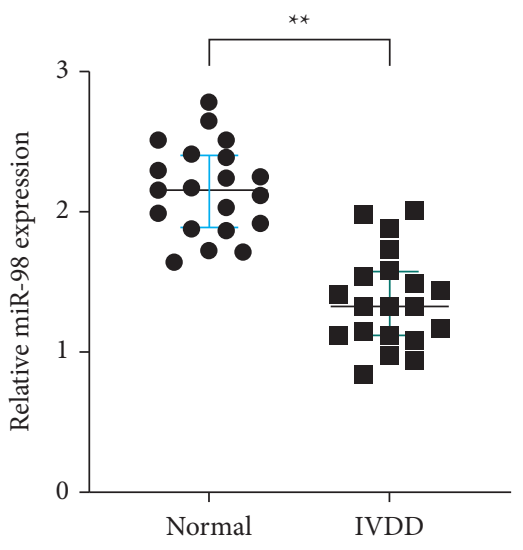

(a)
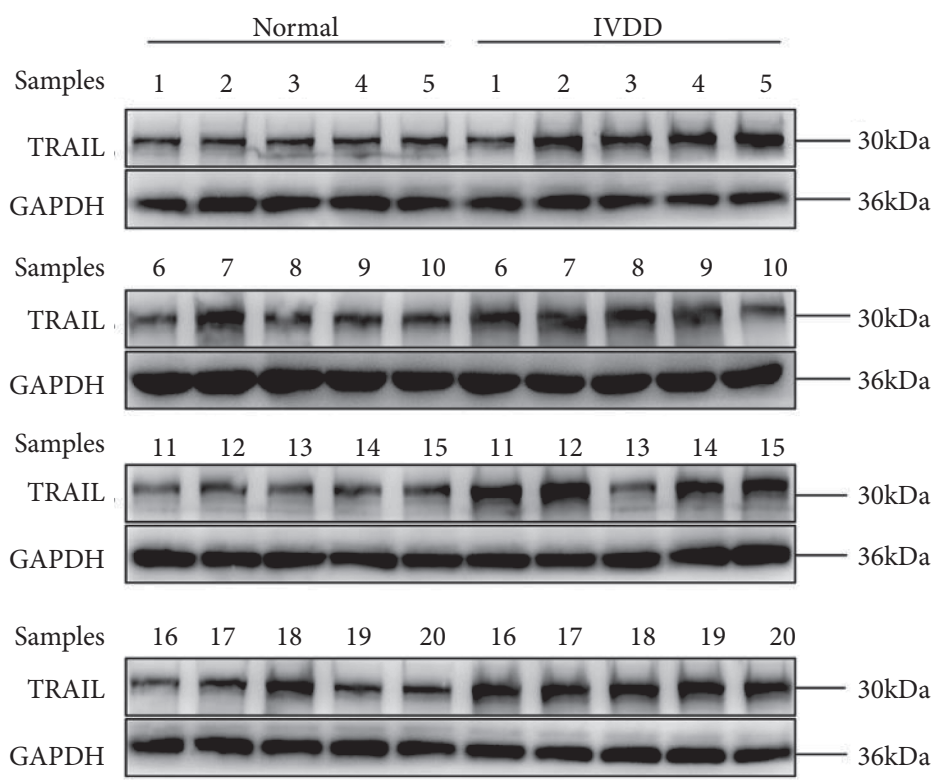

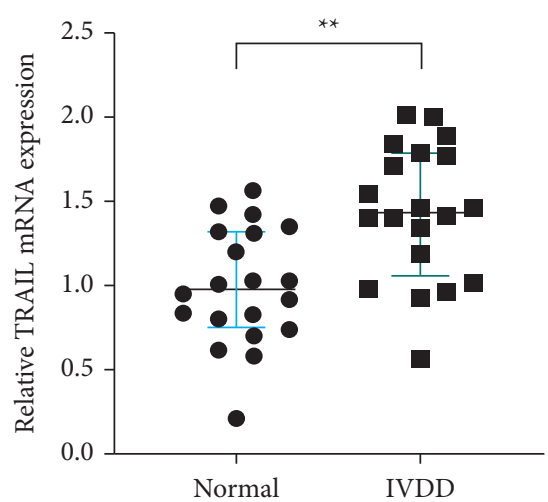

(b)

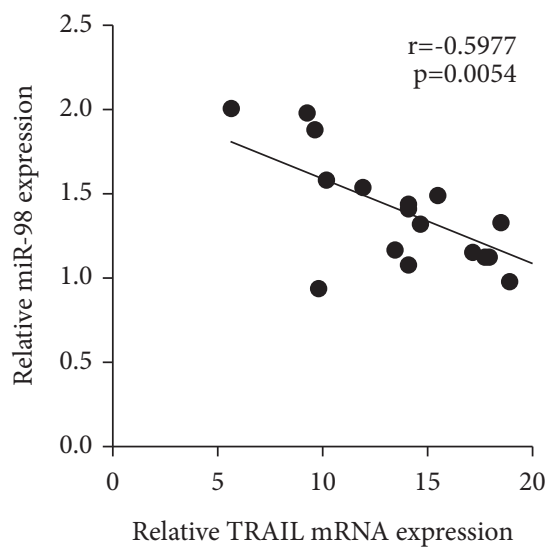

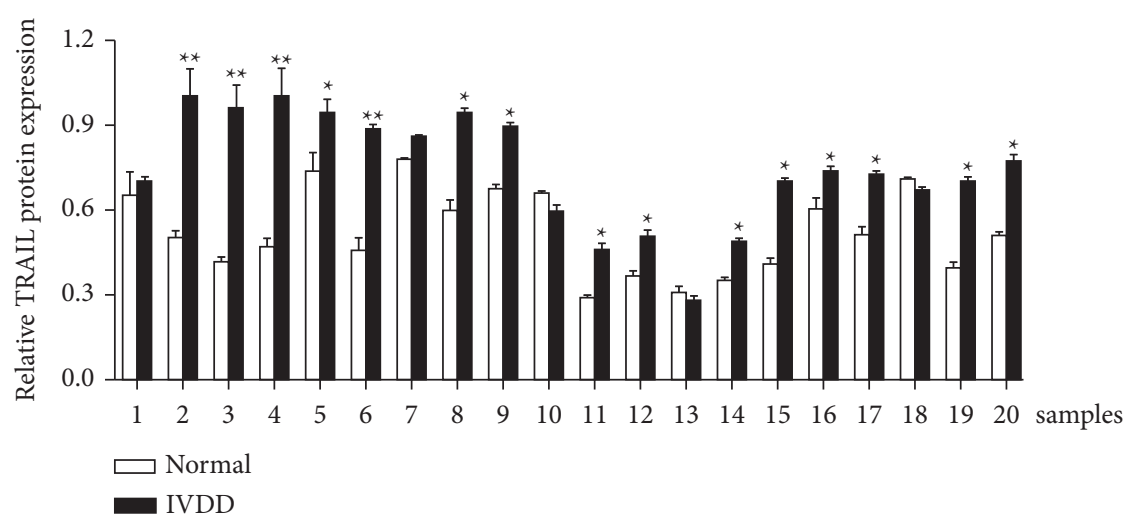

(c) (d)

FIGURE 1: TRAIL was highly expressed while miR-98 was low expressed in patients with IVDD. (a) The results of qRT-PCR showed that the miR-98 expression level significantly downregulated in IVDD NP tissues in comparison with normal NP tissues. $P \leq 0.001$. (b)-(c) The results of qRT-PCR and Western blotting showed that the TRAIL expression level significantly upregulated in IVDD NP tissues compared with normal NP tissues. $P \leq 0.001$. (d) The correlation between the expression level of TRAIL and miR-98 showing a negative correlation in IVDD NP tissues. ${ }^{*} P<0.05$ and ${ }^{*} P<0.01$. 


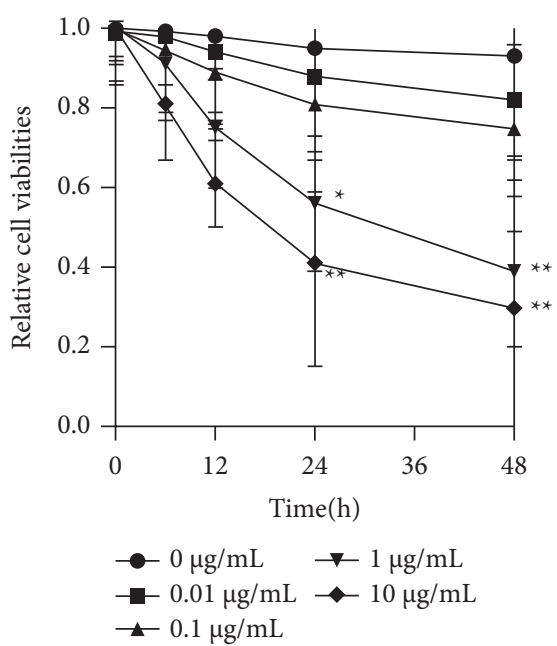

(a)

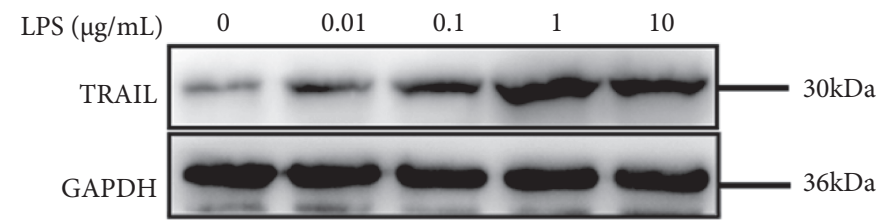

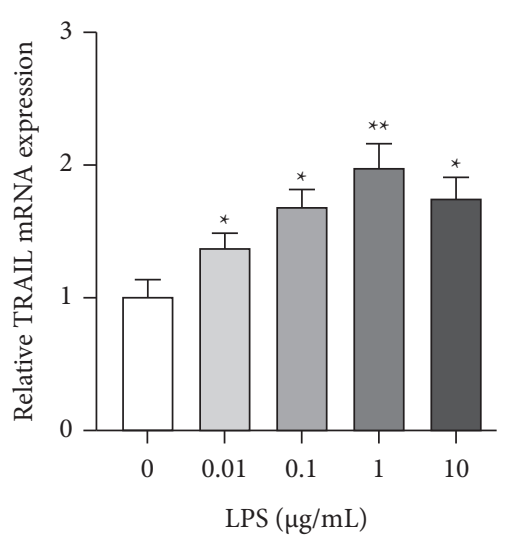

(b)

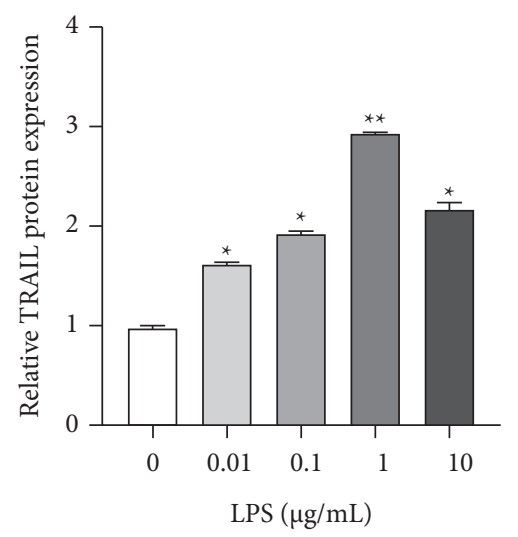

(c)

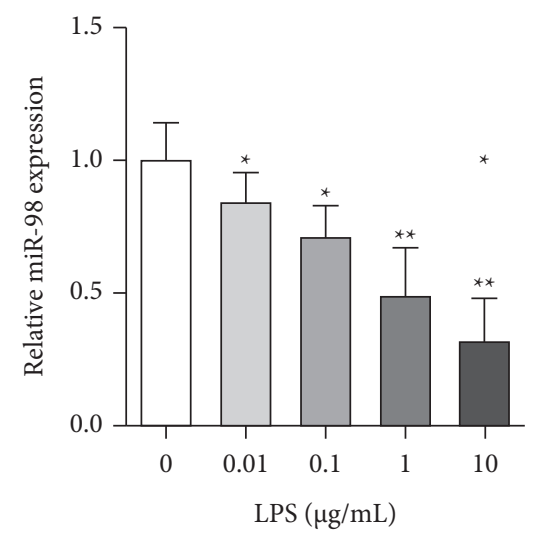

(d)

Figure 2: Establishment of the IVDD cell model. (a) The NP cells treated with different concentrations and different times of LPS and MTT assay performed to determine the cell viability. (b)-(d) qRT-PCR and Western blotting performed to examine miR-98 and TRAIL expression levels in the NP cells treated by LPS. ${ }^{*} P<0.05$ and ${ }^{*} P<0.01$.

that miR-98 significantly enhanced the cell viability and suppressed cell apoptosis, and its effects could be effectively reversed by TRAIL $(P<0.01$; Figures $5(\mathrm{c})$ and $5(\mathrm{~d}))$.

3.6. MiR-98 Targeted TRAIL to Inhibit the Apoptosis of NP Cells via Inactivation of the TRAIL-Signaling Pathway. To assess the roles of miR-98 on the inactivation of the TRAILsignaling pathway, the NP cells stimulated with LPS were divided into 5 groups as described above. Then, we measured the expressions of DR5, FADD, caspase8, cleaved caspase8, caspase3, cleaved caspase3, PARP, and cleaved PARP by Western blotting (Figure 6(a)). The results demonstrated that the levels of DR5, FADD, cleaved caspase8, cleaved caspase3, and cleaved PARP were significantly increased in the LPS-stimulated group in comparison with the control $(P<0.01)$. Transfection of miR-98 mimics significantly inhibited the pathway by downregulating the expressions of DR5, FADD, cleaved caspase8, cleaved caspase3, and cleaved PARP in LPS + miR-98 mimics + pcDNA-NC in comparison to those in LPS + pcDNA-NC $(P<0.01)$. While, transfection of pcDNA-TRAIL partially reversed the inhibitory of miR98 mimics and markedly activated this pathway by upregulating their levels in LPS + miR-98 mimics + pcDNATRAIL in comparison with that in LPS + miR-98 mimics + pcDNA-NC $(P<0.01$; Figure 6(a)). The immunofluorescence analysis of DR5 and cleaved caspase8 obtained similar results (Figures 6(b) and 6(c)). These results above 


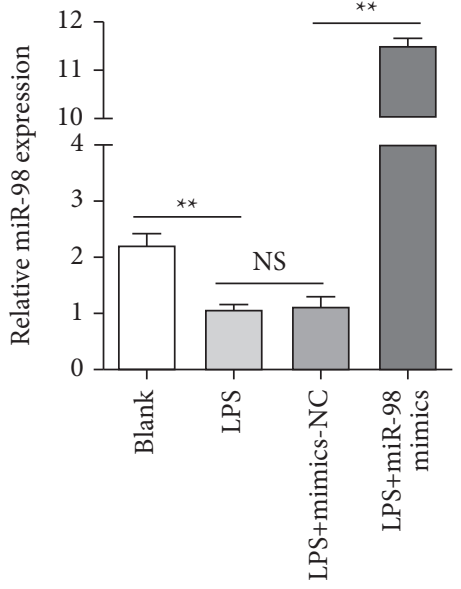

(a)

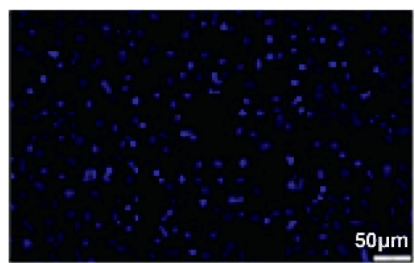

Blank

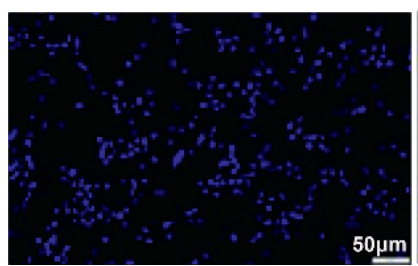

LPS+mimics-NC

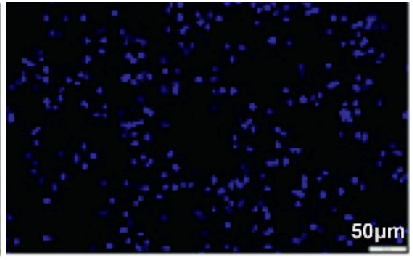

LPS

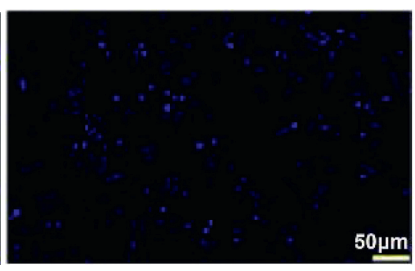

LPS+miR-98 mimics

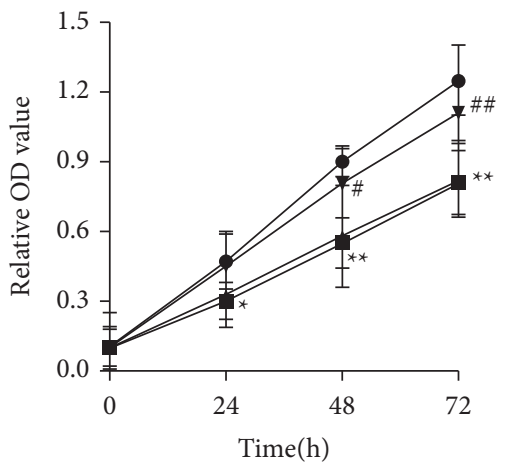

$$
\begin{aligned}
& \text { — Blank } \\
& \text { - LPS } \\
& \text { - LPS+mimics-NC } \\
& \leftarrow \text { LPS+miR-98 mimics }
\end{aligned}
$$

(b)

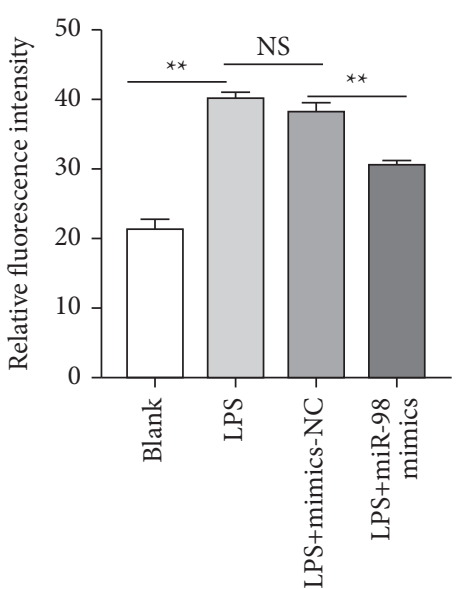

(c)
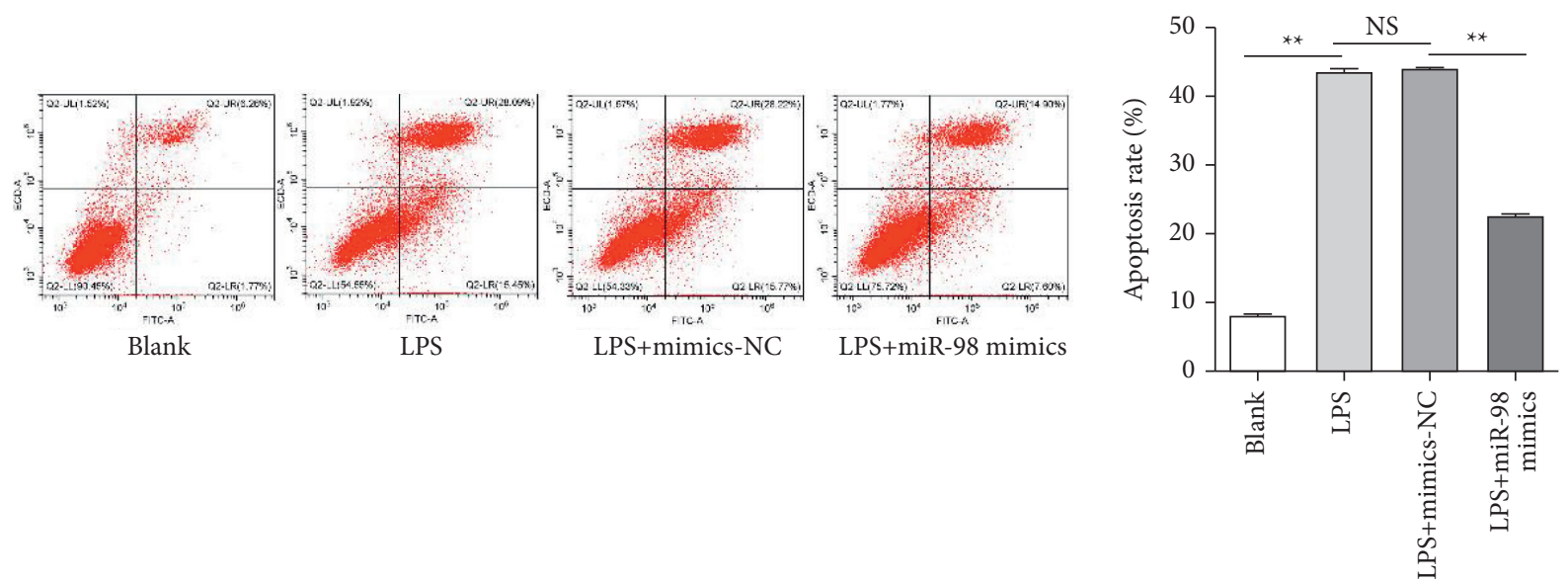

(d)

Figure 3: Overexpression of miR-98 decreased LPS-induced NP cell apoptosis. (a) Transfection efficiency of mimics-NC, miR-98 mimics determined by qRT-PCR. (b) The cell viability of NP cells treated with LPS performed by MTT assay. (c)-(d) NP cell apoptosis after different treatments (blank, LPS, LPS + mimics-NC, and LPS + miR-98 mimics) analyzed by Hoechst 33258 staining and flow cytometry. ${ }^{*} P<0.05$ and ${ }^{*} P<0.01 ;{ }^{\#} P<0.05$ and ${ }^{\# \#} P<0.01$. Scale bars: $50 \mu \mathrm{m}$. 


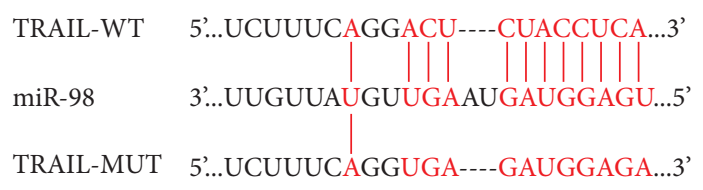

(a)

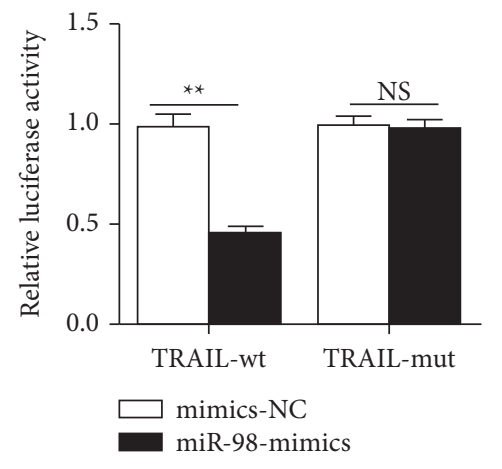

(b)

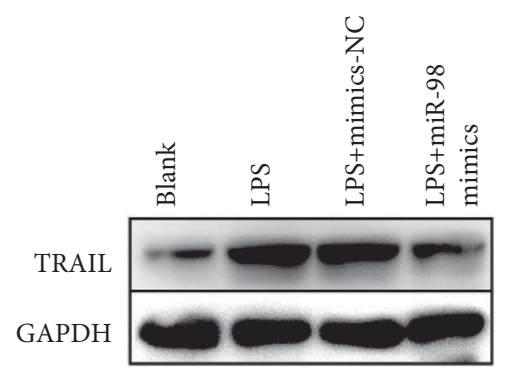

(d)
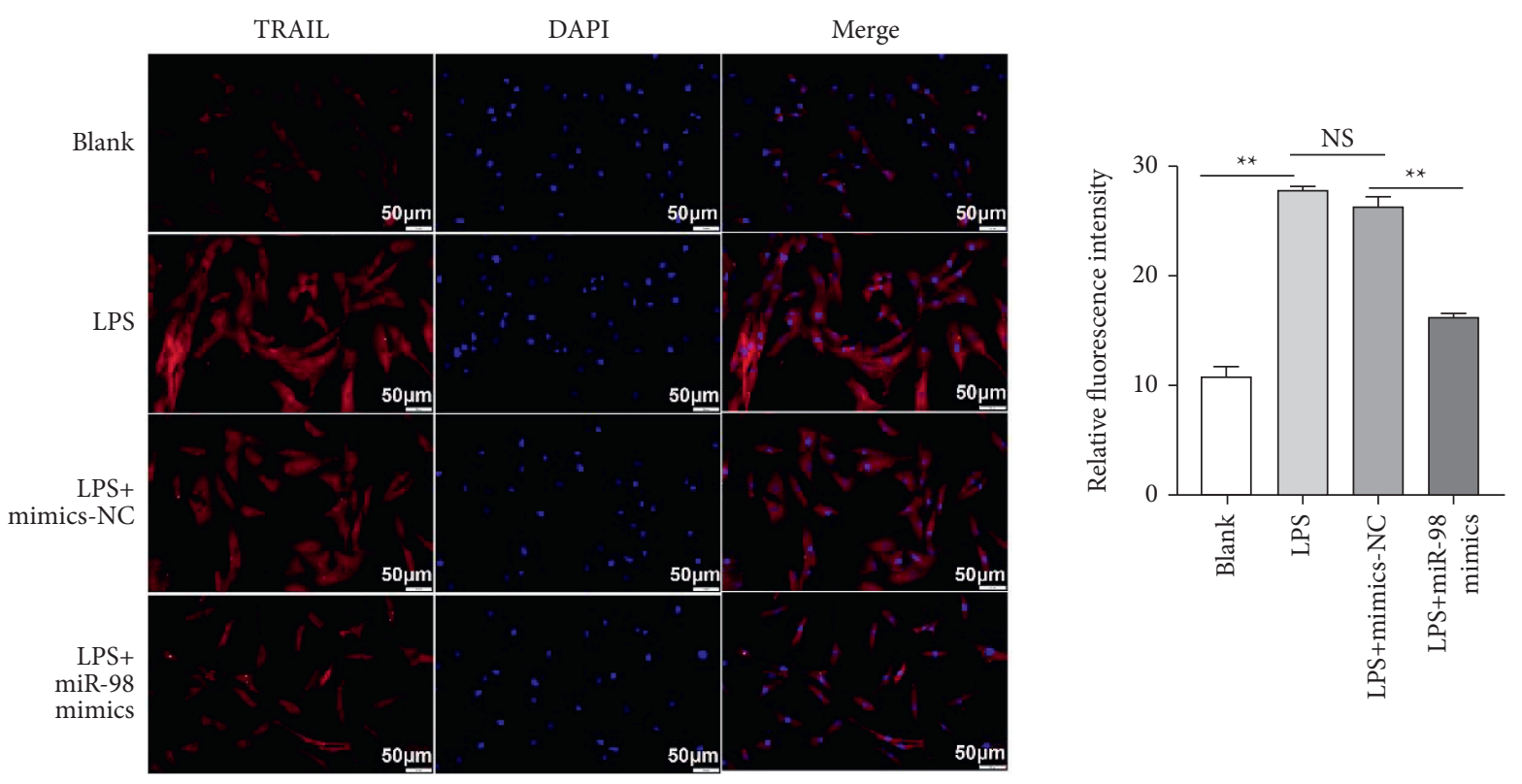

(e)

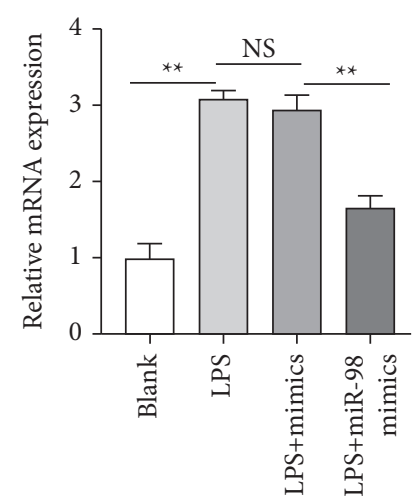

(c)

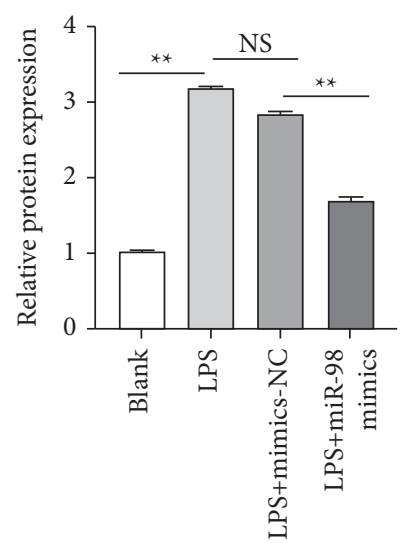




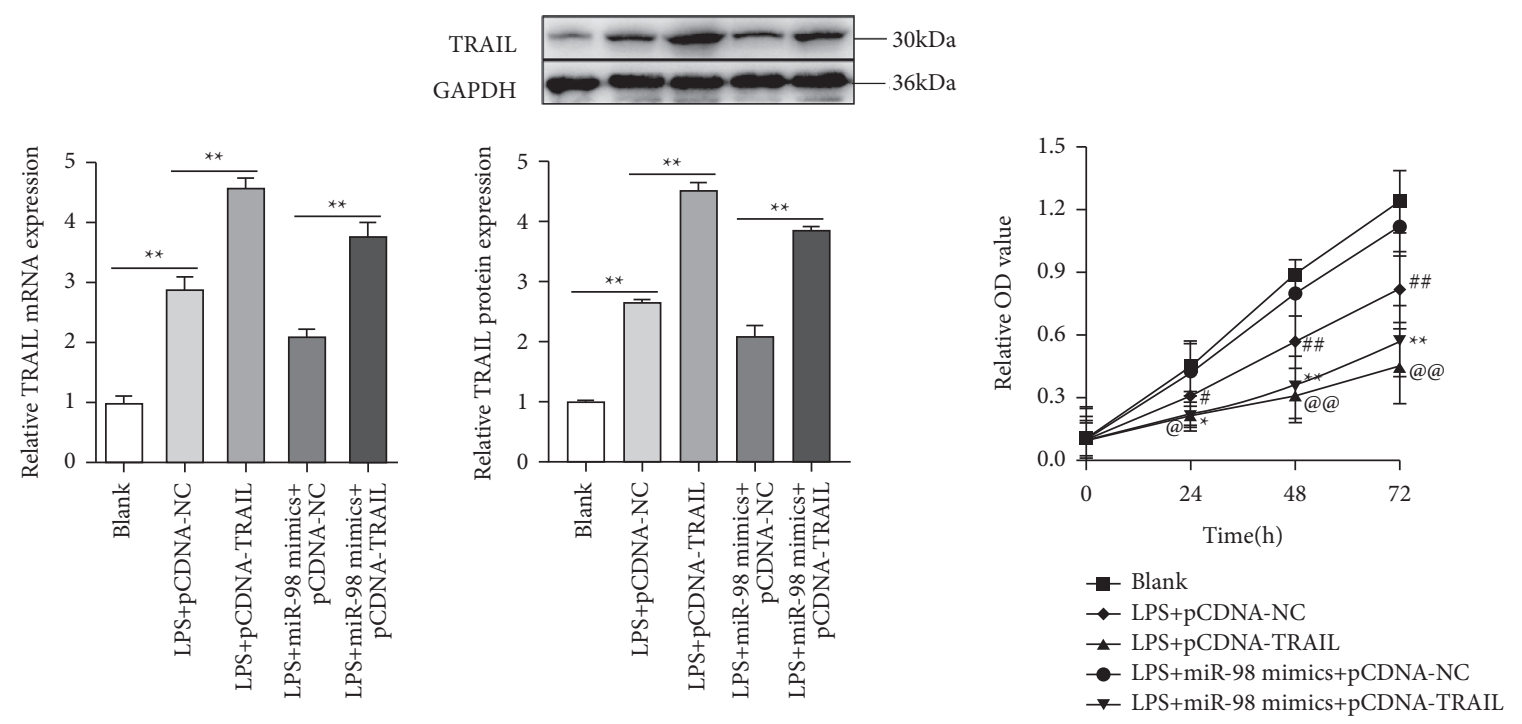

(a)
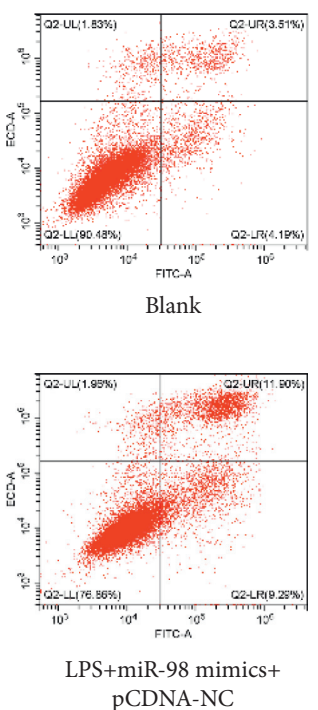

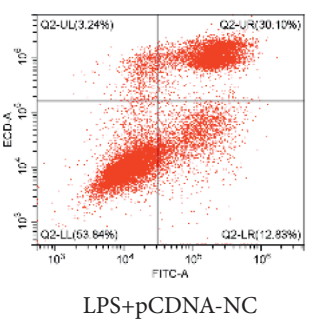

(b)
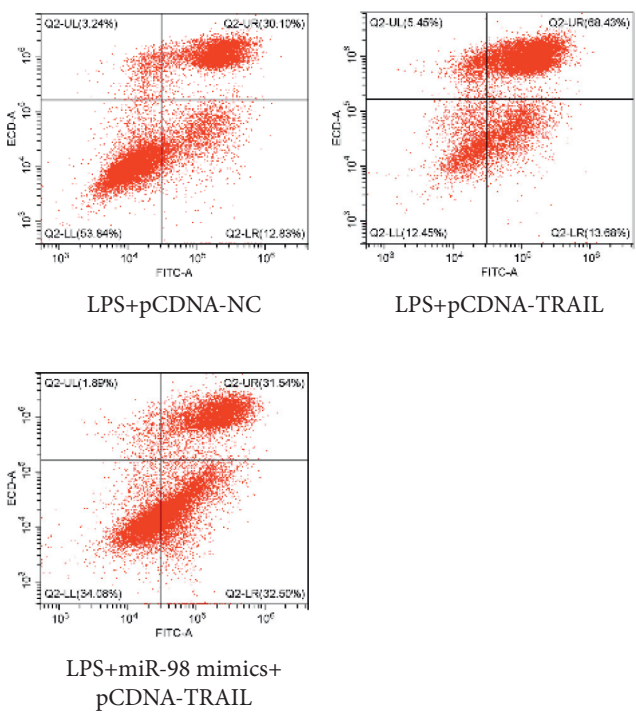

(c)

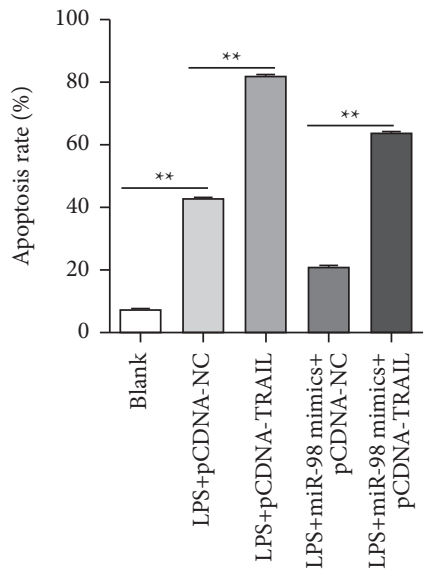

(d)

FIGURE 5: Overexpression of TRAIL reversed the inhibitory effects of miR-98 mimics on NP cell apoptosis stimulated by LPS. (a) Transfection efficiency of pcDNA-NC, pcDNA-TRAIL determined by qRT-PCR. (b) TRAIL protein levels determined by Western blot analysis in different groups (blank, LPS + pcDNA-NC, LPS + pcDNA-TRAIL, LPS + miR-98 mimics + pcDNA-NC, and LPS + miR-98 mimics + pcDNA-TRAIL). (c) The cell viability of NP cells performed by MTT assay in different groups (blank, LPS + pcDNA-NC, LPS + pcDNA-TRAIL, LPS + miR-98 mimics + pcDNA-NC, and LPS + miR-98 mimics + pcDNA-TRAIL). (d) NP cell apoptosis analyzed by flow cytometry in different groups (blank, LPS + pcDNA-NC, LPS + pcDNA-TRAIL, LPS + miR-98 mimics + pcDNA-NC, and LPS + miR98 mimics + pcDNA-TRAIL). ${ }^{*} P<0.05$ and ${ }^{*} P<0.01 ;{ }^{\#} P<0.05$ and ${ }^{\# \#} P<0.01$; ${ }^{@} P<0.05$ and ${ }^{@} \mathrm{Q}<0.01$.

showed that LPS activated the TRAIL-signaling pathway, and the suppressive effects of miR-98 on this pathway could be counteracted by TRAIL.

\section{Discussion}

IVDD is a multifactorial disease, but its pathogenesis is still not completely cleared. Degradation of the extracellular matrix, cell loss (apoptosis), and inflammation are all the prevalent pathological changes in IVDD, which are associated with disc degeneration [22]. According to the understanding of IVDD and current knowledge, there are several limitations in standard therapy, such as modest success rates, invasiveness, and high costs [23]. It has been reported that miRNAs were being the most promising approach for IVDD [24]. Particular attention has been paid to the expression of miRNAs and their functions in relieving the symptoms of IVDD. The studies conducted in vivo experiments using the IVDD rat model identified that miR-185 and miR-143-5p were connected with NP cell apoptosis in IVDD $[25,26]$. miR-98 could reduce apoptosis in many diseases, such as sepsis and acute myocardial infarction $[27,28]$. Nevertheless, the roles of miR-98 in NP cell apoptosis has not yet been studied. In the current study, we discovered that the miR-98 level was lower in IVDD tissues, 


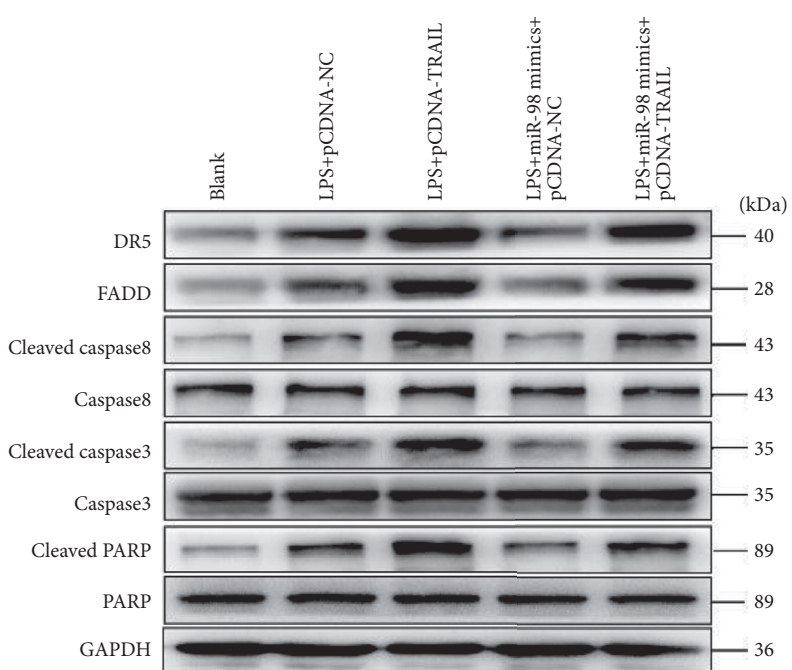

(a)
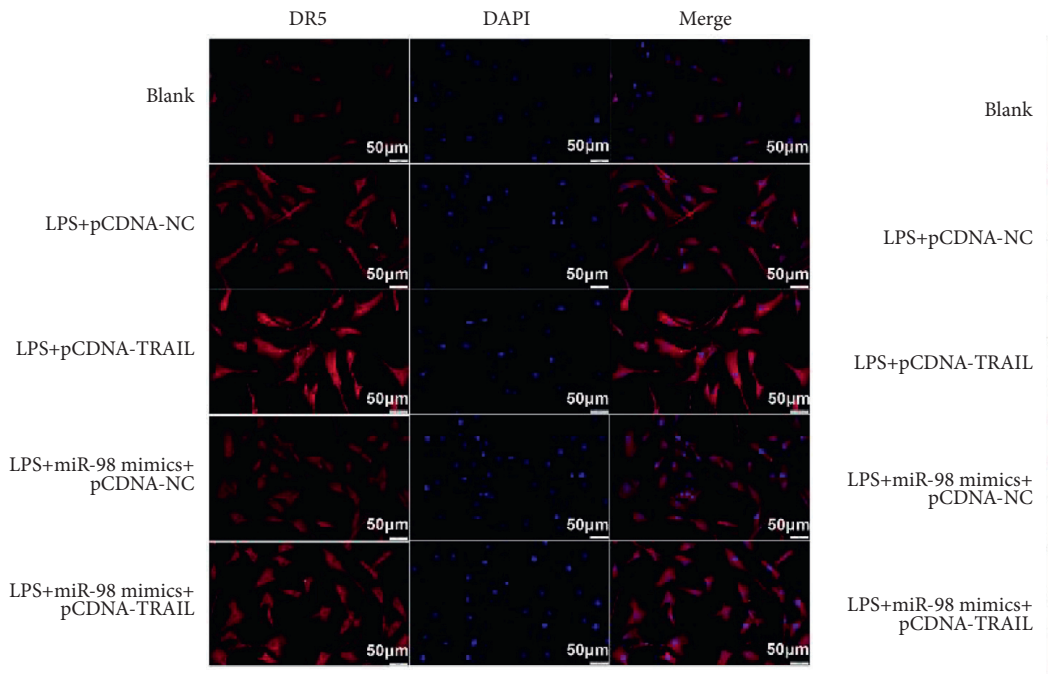

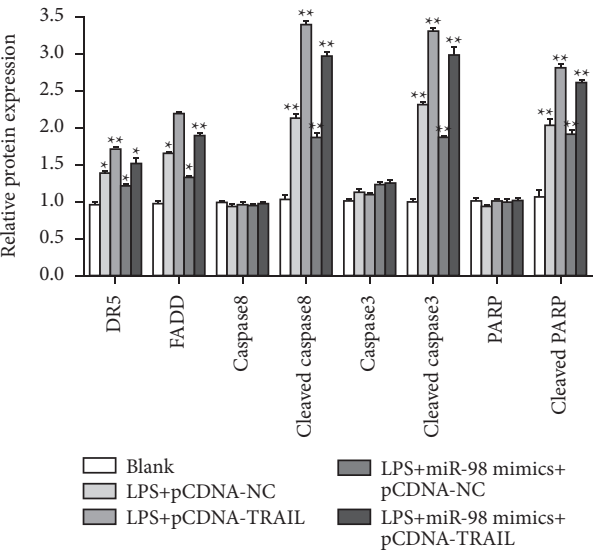

Cleaved caspase8 DAPI

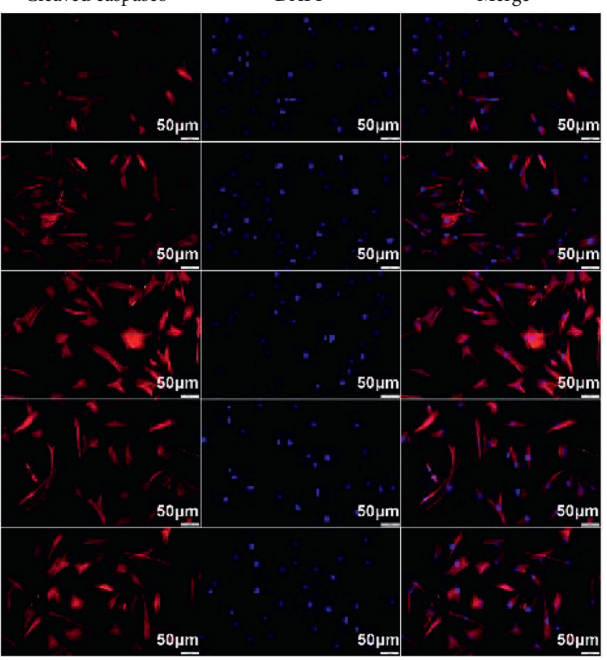

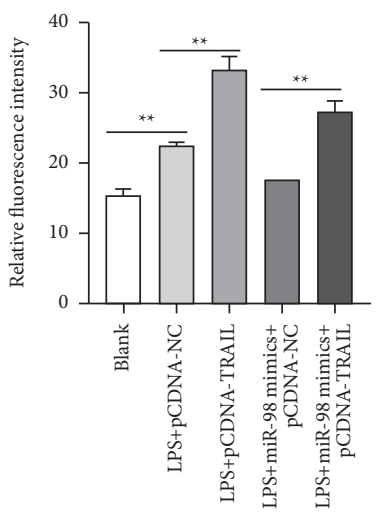

(b)

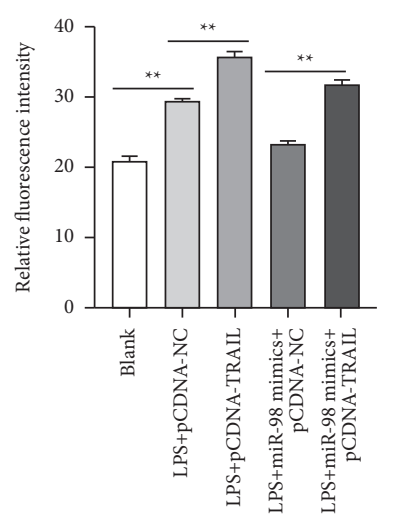

(c)

FIGURE 6: Overexpression of TRAIL reversed the inhibitory effects of miR-98 on the TRAIL pathway. (a) The protein expression levels of DR5, FADD, cleaved caspase8, caspase8, cleaved caspase3, caspase3, cleaved PARP, and PARP examined by Western blot analysis in different groups (blank, LPS + pcDNA-NC, LPS + pcDNA-TRAIL, LPS + miR-98 mimics + pcDNA-NC, and LPS + miR-98 mimics + pcDNA-TRAIL). (b)-(c). The expression levels of DR5 and cleaved caspase8 also detected by immunofluorescence assay in different groups (blank, LPS + pcDNA-NC, LPS + pcDNA-TRAIL, LPS + miR-98 mimics + pcDNA-NC, and LPS + miR-98 mimics + pcDNATRAIL). ${ }^{*} P<0.05$ and ${ }^{*} P<0.01$. Scale bars: $50 \mu \mathrm{m}$. 
while the level of TRAIL was significantly higher, and both of them were associated with the grade of disc degeneration. Ji et al.' study also reported similar results [9]. In addition, we also found that there was a negative relationship between the expression of miR-98 and TRAIL levels. NP cell apoptosis played a key role in IVDD, which is mainly induced by TRAIL [12]. To explore the inhibition of miR-98 on apoptosis of NP cells in IVDD, we studied the association between TRAIL and miR-98 in NP cells.

LPS, as a potent inducer of inflammation, can bind to TLR4 and induce cell apoptosis by promoting the production of TRAIL $[29,30]$. Thus, in the current study, LPS was used to establish the IVDD cell model for research; then, we obtained the results that the expression of miR-98 was dropped in human NP cells by LPS stimulation, while TRAIL expressions were raised. These results were similar to the previous studies which indicated that the miR-98 level was significantly decreased following LPS stimulation $[31,32]$, while LPS could increase the expression of TRAIL $[30,33,34]$. In the present study, compared with the stimulation with LPS only, cell apoptosis was suppressed by the overexpression of miR-98. Our study proved that miR98 played a key role in IVDD partially by inhibiting NP cell apoptosis. These results accorded closely with the previous study of Ji et al. [9].

The putative binding region of miR-98 in $3^{\prime}$-UTR TRAIL was mutated, and a dual-luciferase gene reporter assay demonstrated that miR-98 targeted TRAIL directly; this result was consistent with the previous study of Jong et al. [10]. We also observed that TRAIL expression was significantly reduced following transfection of miR-98 mimics. Besides, to better explore the role of TRAIL in IVDD, pcDNA-TRAIL was transfected into the NP cells, and the results suggested that TRAIL reversed the inhibitory role of miR-98 mimics on the apoptosis of LPS-treated NP cells.

It is well known that the TRAIL-signaling pathway mediates the apoptosis of NP cells in IVDD. DR5, FADD, caspase8, and the downstream caspases are the apoptosis genes involved in the TRAIL-signaling pathway $[12,35]$. Previous studies indicated that TRAIL, DR4, DR5, cleaved caspase8, and cleaved PRAP were highly expressed in IVDD cells, and these protein levels were positively correlated with the degenerative state of the disk $[12,35]$. Li et al. found that, in contrast with the normal group, there was a highly expressed level of FADD in NP cells of rats in the IVDD model group [36]. Overexpression of miR-98 inhibited the upregulation of DR5, FADD, cleaved caspase8, cleaved caspase3, and cleaved PARP expression induced by LPS. The inhibitory effects of miR-98 mimics on the apoptosis genes expressions could be reversed by the transfection of pcDNA-TRAIL.

\section{Conclusion}

This study found that miR-98 expression was dropped in IVDD and participated in the apoptosis of NP cells by inhibiting TRAIL. More functional model experiments in vivo are needed in the future to verify the effect of miR-98 on IVDD. MiR-98 alleviated IVDD by decreasing the apoptosis of NP cells through inhibiting TRAIL and its downstream apoptosis genes expressions in NP cells. The results provided a deeper opinion into the study of IVDD and suggested that miR-98 might prove to be of regulatory importance of IVDD.

\section{Abbreviations}

NP: $\quad$ Nucleus pulposus

IVDD: Intervertebral disc degeneration

LPS: Lipopolysaccharide

MiR: $\quad$ MicroRNA

FADD: Fas-associated death domain

DISC: Death-inducing signaling complex

PCR: Polymerase chain reaction

TRAIL: TNF-related apoptosis-inducing ligand

TLR4: Toll-like receptor 4 .

\section{Data Availability}

The data used to support the findings of this study are available from the corresponding author upon request.

\section{Ethical Approval}

This study was approved by the Research Ethics Committee of Weifang People's Hospital and obeyed the principles of the Declaration of Helsinki.

\section{Conflicts of Interest}

The authors declare that they have no conflicts of interest.

\section{Authors' Contributions}

Shimin $\mathrm{Xu}$ conceptualized and designed the study and wrote the article. Yuezhong Li involved in acquisition of data. Junshan Zhang and Zhiwei Li analyzed the data. Yanping Xing modified the manuscript. All authors gave final approval of the version to be published and agreed to be accountable for all aspects of the work.

\section{References}

[1] E. Okada, M. Matsumoto, D. Ichihara et al., "Aging of the cervical spine in healthy volunteers," Spine, vol. 34, no. 7, pp. 706-712, 2009.

[2] M. A. Adams and P. J. Roughley, "What is intervertebral disc degeneration, and what causes it?" Spine, vol. 31, no. 18, pp. 2151-2161, 2006.

[3] N. Epstein and R. Hollingsworth, "Nursing review section of Surgical Neurology International: Part 1 lumbar disc disease," Surgical Neurology International, vol. 8, no. 1, p. 301, 2017.

[4] J. F. Ma, L. N. Zang, Y. M. Xi, W. J. Yang, and D. Zou, "MiR-125a Rs12976445 polymorphism is associated with the apoptosis status of nucleus pulposus cells and the risk of intervertebral disc degeneration," Cellular Physiology and Biochemistry, vol. 38, no. 1, pp. 295-305, 2016.

[5] D. Sakai, J. Mochida, T. Iwashina et al., "Atelocollagen for culture of human nucleus pulposus cells forming nucleus pulposus-like tissue in vitro: influence on the proliferation and proteoglycan production of HNPSV-1 cells," Biomaterials, vol. 27, no. 3, pp. 346-353, 2006. 
[6] T. Wang, P. Li, X. Ma et al., "MicroRNA-494 inhibition protects nucleus pulposus cells from TNF- $\alpha$-induced apoptosis by targeting JunD," Biochimie, vol. 115, pp. 1-7, 2015.

[7] Y. Sun, X. Shi, X. Peng et al., "MicroRNA-181a exerts antiinflammatory effects via inhibition of the ERK pathway in mice with intervertebral disc degeneration," Journal of Cellular Physiology, vol. 235, no. 3, pp. 2676-2686, 2020.

[8] Y.-q. Xu, Z.-h. Zhang, Y. F. Zheng, and S.-q. Feng, "Dysregulated miR-133a mediates loss of type II collagen by directly targeting matrix metalloproteinase 9 (MMP9) in human intervertebral disc degeneration," Spine, vol. 41, no. 12, pp. E717-E724, 2016.

[9] M.-1. Ji, J. Lu, P.-1. Shi et al., "Dysregulated miR-98 contributes to extracellular matrix degradation by targeting IL-6/STAT3 signaling pathway in human intervertebral disc degeneration," Journal of Bone and Mineral Research, vol. 31, no. 4, pp. 900-909, 2016.

[10] V. M. de Jong, A. R. van der Slik, S. Laban et al., "Survival of autoreactive T lymphocytes by microRNA-mediated regulation of apoptosis through TRAIL and Fas in type 1 diabetes," Genes and Immunity, vol. 17, no. 6, pp. 342-348, 2016.

[11] J. Mongkolsapaya, J. M. Grimes, N. Chen et al., "Structure of the TRAIL-DR5 complex reveals mechanisms conferring specificity in apoptotic initiation," Nature Structural Biology, vol. 6, no. 11, pp. 1048-1053, 1999.

[12] H. Bertram, A. Nerlich, G. Omlor, F. Geiger, G. Zimmermann, and J. Fellenberg, "Expression of TRAIL and the death receptors DR4 and DR5 correlates with progression of degeneration in human intervertebral disks," Modern Pathology, vol. 22, no. 7, pp. 895-905, 2009.

[13] M. P. Boldin, T. M. Goncharov, Y. V. Goltseve, and D. Wallach, "Involvement of MACH, a novel MORT1/FADDinteracting protease, in Fas/APO-1- and TNF receptor-induced cell death," Cell, vol. 85, no. 6, pp. 803-815, 1996.

[14] J. P. Medema, C. Scaffidi, F. C. Kischkel et al., "FLICE is activated by association with the CD95 death-inducing signaling complex (DISC)," The EMBO Journal, vol. 16, no. 10, pp. 2794-2804, 1997.

[15] M. Muzio, G. S. Salvesen, and V. M. Dixit, "FLICE induced apoptosis in a cell-free system," Journal of Biological Chemistry, vol. 272, no. 5, pp. 2952-2956, 1997.

[16] S.-S. Wang, L. Feng, B.-G. Hu et al., "miR-133a promotes TRAIL resistance in glioblastoma via suppressing death receptor 5 and activating NF- $\kappa \mathrm{B}$ signaling," Molecular TherapyNucleic Acids, vol. 8, pp. 482-492, 2017.

[17] H. Kumar, T. Kawai, and S. Akira, "Toll-like receptors and innate immunity," Biochemical and Biophysical Research Communications, vol. 388, no. 4, pp. 621-625, 2009.

[18] S. W. Leu, L. Shi, C. Xu et al., "TLR4 through IFN- $\beta$ promotes low molecular mass hyaluronan-induced neutrophil apoptosis," Journal of Immunology, vol. 186, no. 1, pp. 556-562, 2011.

[19] C. W. A. Pfirrmann, A. Metzdorf, M. Zanetti, J. Hodler, and $\mathrm{N}$. Boos, "Magnetic resonance classification of lumbar intervertebral disc degeneration," Spine, vol. 26, no. 17, pp. 1873-1878, 2001.

[20] H. D. VanGuilder, K. E. Vrana, and W. M. Freeman, "Twenty-five years of quantitative PCR for gene expression analysis," Biotechniques, vol. 44, no. 5, pp. 619-626, 2008.

[21] Y. Zhang, J. Yang, X. Zhou et al., "Knockdown of miR-222 inhibits inflammation and the apoptosis of LPS-stimulated human intervertebral disc nucleus pulposus cells," International Journal of Molecular Medicine, vol. 44, no. 4, pp. 1357-1365, 2019.
[22] J. Clouet, C. Vinatier, C. Merceron et al., "The intervertebral disc: from pathophysiology to tissue engineering," Joint Bone Spine, vol. 76, no. 6, pp. 614-618, 2009.

[23] P. Cazzanelli and K. Wuertz-Kozak, "MicroRNAs in intervertebral disc degeneration, apoptosis, inflammation, and mechanobiology," International Journal of Molecular Sciences, vol. 21, no. 10, 2020.

[24] N. Henry, J. Clouet, J. Le Bideau, C. Le Visage, and J. Guicheux, "Innovative strategies for intervertebral disc regenerative medicine: from cell therapies to multiscale delivery systems," Biotechnology Advances, vol. 36, no. 1, pp. 281-294, 2018.

[25] Z. Yun, Y. Wang, W. Feng, J. Zang, D. Zhang, and Y. Gao, "Overexpression of microRNA-185 alleviates intervertebral disc degeneration through inactivation of the $\mathrm{Wnt} / \beta$-catenin signaling pathway and downregulation of Galectin-3," Molecular Pain, vol. 16, Article ID 1744806920902559, 2020.

[26] Q. Yang, X.-P. Guo, Y.-L. Cheng, and Y. Wang, "MicroRNA143-5p targeting eEF2 gene mediates intervertebral disc degeneration through the AMPK signaling pathway," Arthritis Research and Therapy, vol. 21, no. 1, p. 97, 2019.

[27] J. Zhu, X. Lin, C. Yan, S. Yang, and Z. Zhu, "microRNA-98 protects sepsis mice from cardiac dysfunction, liver and lung injury by negatively regulating HMGA2 through inhibiting NF- $\kappa \mathrm{B}$ signaling pathway," Cell Cycle, vol. 18, no. 16, pp. 1948-1964, 2019.

[28] C. Sun, H. Liu, J. Guo et al., "MicroRNA-98 negatively regulates myocardial infarction-induced apoptosis by down-regulating Fas and caspase-3," Scientific Reports, vol. 7, no. 1, p. 7460, 2017.

[29] S.-B. Jung, C.-S. Yang, J.-S. Lee et al., "The mycobacterial 38-kilodalton glycolipoprotein antigen activates the mitogen-activated protein kinase pathway and release of proinflammatory cytokines through Toll-like receptors 2 and 4 in human monocytes," Infection and Immunity, vol. 74, no. 5, pp. 2686-2696, 2006.

[30] D. Kwon, J. H. Cheong, J.-C. Lee, J.-H. Kwon, and W.-K. Kim, "Lipopolysaccharides-activated human astroglioma cells induce apoptotic death of T-lymphocytes via c-Jun $\mathrm{N}$-terminal kinases-dependent up-regulation of TRAIL," Neuroscience Research, vol. 54, no. 4, pp. 338-343, 2006.

[31] Y. Liu, Q. Chen, Y. Song et al., "MicroRNA-98 negatively regulates IL-10 production and endotoxin tolerance in macrophages after LPS stimulation," FEBS Letters, vol. 585, no. 12, pp. 1963-1968, 2011.

[32] G. Hu, R. Zhou, J. Liu et al., "MicroRNA-98 and let-7 confer cholangiocyte expression of cytokine-inducible Src homology 2-containing protein in response to microbial challenge," The Journal of Immunology, vol. 183, no. 3, pp. 1617-1624, 2009.

[33] Y. Yu, S. Liu, W. Wang et al., "Involvement of tumour necrosis factor-alpha-related apoptosis-inducing ligand in enhanced cytotoxicity of lipopolysaccharide-stimulated dendritic cells to activated T cells," Immunology, vol. 106, no. 3, pp. 308-315, 2002.

[34] S. Genc, S. Kizýldag, K. Genc, H. Ates, and N. Atabey, "Interferon gamma and lipopolysaccharide upregulate TNF-related apoptosis-inducing ligand expression in murine microglia," Immunology Letters, vol. 85, no. 3, pp. 271-274, 2003.

[35] B. Chen, B. Ma, S. Yang, X. Xing, R. Gu, and Y. Hu, "DR5 and DcR2 are expressed in human lumbar intervertebral discs," Spine, vol. 34, no. 19, pp. E677-E681, 2009.

[36] N. Li, Q. Gao, W. Zhou, X. Lv, X. Yang, and X. Liu, "MicroRNA-129-5p affects immune privilege and apoptosis of nucleus pulposus cells via regulating FADD in intervertebral disc degeneration," Cell Cycle, vol. 19, no. 8, pp. 933-948, 2020. 